This is an Accepted Manuscript of an article published by Taylor \& Francis in Health Sociology Review on 4 April, 2019, available online:

https://www.tandfonline.com/doi/full/10.1080/14461242.2019.1604150

Fat acceptance 101: Midwestern American women's perspective on cultural body acceptance

Andrea E Bombak, Angela Meadows, \& Jacqueline Billette

The final version of record is published in Health Sociology Reviewer, vol 28(2),

194-208. DOI: 10.1080/14461242.2019.1604150 


\title{
Fat acceptance 101: Midwestern American women's perspective on cultural body acceptance
}

\begin{abstract}
Weight stigma is pervasive in the US, with body size being pathologised and weight loss urged for those of higher weights. However, there is a growing movement for fat acceptance and body positivity. The present study explored perceptions and experiences of cultural body acceptance trends among Midwestern American women who are trying to, or have tried to, "accept" their bodies. Participants $(n=18)$ are self-identified women who have ever been labelled 'obese' on the Body Mass Index and have ever tried to develop a more positive relationship with their bodies. Participants were interviewed three times over the course of approximately one year using a semi-structured interview guide that explored their perceptions of how society represented and treated those of a higher weight. Interviews were recorded and transcribed verbatim, and interviews and field-notes analysed thematically. Emergent themes included: greater (mixed) representation, lip service, and inclusive cultures. Ultimately, participants positioned shifting attitudes towards fat bodies within wider social trends toward greater inclusion and diversity in general, but remained frustrated by ceilings of acceptable size, disingenuous messaging, and cultural backsliding.
\end{abstract}

Keywords: fat activism, body acceptance, fat studies, critical weight studies, media representation, diversity 


\section{Introduction}

Weight dissatisfaction among Western women (and increasingly men) is so pervasive as to be described as "normative discontent" (Rodin, Silberstein, \& Streigel-Moore, 1984; Tantleff-Dunn, Barnes, \& Larose, 2011). Although individuals across the weight spectrum face pressure to conform to the "thin ideal", those whose body weight exceeds culturally acceptable norms face additional stigma and discrimination in almost every sphere of daily life. Women are disproportionately targeted by weight-related stigma, experiencing it at lower weights than men (Hatzenbuehler, Keyes, \& Hasin, 2009) and reporting higher weight dissatisfaction and weight bias internalisation (Blake et al., 2013; Himmelstein, Puhl, Quinn, \& Gorber, 2017). However, increasing numbers of scholars and healthcare professionals are now challenging the rhetoric of the "war on obesity" (O'Hara \& Taylor, 2018), and while the late $20^{\text {th }}$ century and the first decade of the $21^{\text {st }}$ century were marked by the emergence of a multi-billion pound diet industry (Germov \& Williams, 1996) and near universal acquiescence to the dominant discourses around fatness, health, and morality, the last two decades have witnessed the ascendance of a countering paradigm that challenges the pejorative state of fatness and its reductionist linkage to ill health, gluttony, and sloth (Bombak, 2014; Gard \& Wright, 2005). These critical weight discourses have been paralleled by the growth in prominence of the Fat Acceptance movement, which has its roots in fat liberation circles of the mid-20 th century (Cooper, 2016; Lupton, 2018). ${ }^{1}$ In recent years, fat activism has filtered into the mainstream via the proliferation of online spaces and

\footnotetext{
${ }^{1}$ Fatness and fat are used throughout this manuscript in a non-pejorative sense but in line with fat acceptance communities who seek to reclaim these terms as neutral descriptors. To reflect some participants' preferences, the term "higher-weight" is also used. Likewise, "obesity" is presented in quotes to acknowledge the contested meanings of this word and its political implications.
} 
social media channels dedicated to the subject - known as the Fatosphere, through which these messages are becoming part of the wider culture (Afful \& Ricciardelli, 2015).

Body acceptance, refers to the process whereby individuals attempt to renounce the dominant body discourses and achieve a state of comfort in their current body. While the process of body acceptance is often described in online or clinical spaces, little empirical research on fat women's experience of seeking to accept their bodies has been conducted. Further, little is known about how perceptions of cultural shifts in body politics are experienced by individuals engaging in these transformative journeys.

The aim of the present study was to look at how a Midwestern population of current or former higher-weight/fat women discussed enactments of cultural body acceptance/intolerance over the course of approximately one year. This analysis is part of a larger study that examined attempts on behalf of participants to achieve body acceptance. This population was targeted, as it requires that individuals have lived experience in a fat body, be aware of cultural norms regarding the unacceptability of fatness, and have attempted to challenge these dominant discourses in relation to their own higher-weight bodies. Thus, these participants have personally engaged with both the shifting zeitgeist with regards to diverse bodily acceptance and also likely faced challenges associated with undergoing this process within the nevertheless predominantly fat-phobic cultural environment.

\section{Methods}

\section{Participants}

The study setting was a small university city located in a Midwestern county. Participants were self-identified women 18 years of age or over. Participants must have been classified as 'obese' 
on a BMI scale at some point in their lives and have tried to accept their body. In appreciation of the fluidity of body weight, we allowed participants to self-define as having had the experiences of an "obese" person but did not stipulate current weight status. Two of the 18 participants selfclassified as previously but not currently "obese", and one participant reported to the interviewer that she had lost weight over the course of the study, and would now be classified as "overweight". As is to be expected in a longitudinal study, other participants also underwent weight fluctuations throughout the study. Participants were recruited via local health, human services, and university email lists and posters distributed throughout the city and university. Eighteen (18) individuals participated. Most participants identified as White, with two participants identifying as multi-racial. Participants were aged 22 to 61 years (median 37 years), highly educated - 16 had at least a university degree and five had graduate degrees, and most were employed, predominantly in health, human services, or education sectors. Participants were not explicitly asked about sexual orientation, but references to partners/prospective partners were generally male and/or masculine.

\section{Data collection}

Participants were interviewed three times by the first author over the course of approximately one year, with interviews taking part at intervals of between 3 and 5 months. Repeated interviews were chosen to capture change over time in the larger study that examined attempts on behalf of participants to achieve body acceptance. Repeated interviews were also chosen as a means to enhance rigour. They allow for the incorporation of emerging themes into future interviews; for organic member checking and validity assurance during subsequent interviews; strengthened rapport; and data that captures more than a solitary, time and situationally- 
contingent reflection on a phenomenon (Saldaña, 2003; N. Smith, 2003; Thomson \& Holland, 2003).

Participant names used throughout the manuscript are pseudonyms assigned by researchers. All interviews were conducted face-to-face with one exception. The one exception was a third phase interview conducted over the telephone, as a participant had moved out of state. Only one participant was lost to follow-up for the third interview - resulting in a total of 53 interviews. Interviews were audio-recorded and professionally transcribed verbatim. Detailed field-notes on non-verbal communication, possible indications of researcher biases, and affect detectable during interviews were recorded immediately following the interview (Emerson, Fretz, \& Shaw, 2011). Interviews were conducted using a loosely-structured interview guide that asked participants about whether they were detecting any changes in cultural body acceptance and their feelings, preferences, experiences and attitudes regarding those changes. The study was approved by the first author's Institutional Review Board.

\section{Analysis}

Transcripts and field-notes were uploaded into NVivo 11 (QSR International) at each time point and analysed immediately. Interviews were analysed thematically following both inductive and deductive procedures (Elo \& Kyngäs, 2008). The transcript and field-notes for the first participant were read repeatedly and annotated based on the participant's own literal language choices (in vivo coding) and based on underlying meanings (concept coding) (Saldaña, 2016). These annotations were gathered and assigned to conceptual categories to construct an everevolving master 'code-book'. All interviews were read repeatedly, and every segment of text was assigned to relevant codes from the 'code book'. After all interviews were initially analysed 
according to this first code book, the codes were collapsed into broader categories and emergent themes based on their location, frequency, and patterns of usage within the interviews (Elo \& Kyngäs, 2008). Memos were created that summarised each interview and related field-notes for every participant and to identify emerging patterns and themes. An ongoing audit-trail, a record kept by the analyst during coding and categorisation, was maintained during the analysis process and to ensure that the same meaning units were reliably being assigned to particular codes. Tables were then constructed to summarise each participants' responses pertaining to emergent themes and research questions to allow for cross-comparison between participants and timepoints. References participants made to body acceptance and culture from every interview were tabulated and annotated along with notes on how each participant described their lifestyle, relationship, health, body acceptance, and changes over the course of data collection. As we compared responses over time-points and between participants (Saldaña, 2003), we began to draw from previous research on bodies and fatness - what Wright (2004) has named the mapping of a field - to arrive at interpretations of participants' perceptions of cultural body acceptance.

\section{Findings}

Participants described changes they witnessed to body acceptance in terms of three main themes: greater (mixed) representation, lip service, and inclusive culture. In general, participants remained consistent in their view of cultural change over the course of the interviews. Most, but not all, participants felt society was becoming more accepting of larger bodies or noted subtle indications of increasing acceptance for larger (but not all) bodies. Many reiterated similar trends over the course of interviews but brought in new examples of body acceptance/oppression they encountered, or contacted the interviewer between interviews with more examples. Perceptions of the direction of cultural change did not vary according to participants' weight status. 


\section{Greater (Mixed) Representation}

Most participants felt society had become more accepting of higher-weight bodies over time, usually referring to greater representation of larger bodies in mass media or the availability and visibility of 'plus-size' clothing as evidence of emerging representation:

Definitely, like, the campaigns have been really, like, great. ... a lot of stores, like um, Meijer just put their plus-size clothes- Clothing in the regular clothing, notLike, it's not a separate thing. (Mia)

In her first interview, Harper listed several examples of body acceptance she felt were emergent in the culture, including the Dove Real Beauty campaign and major female Hollywood actors who refused to lose weight or be airbrushed. In her second interview, Harper discussed backlash over body-shaming statues erected of then-Presidential candidate Donald Trump:

It was during the campaign...For the presidency and somebody made naked Donalds and put them in public places and instead of a lot, I would say $50 \%$ of the people that saw that laughed and thought it was hilarious. And the other $50 \%$ said ... of all the things to make fun of why are you making fun of his body? That's not right. If you don't like his politics that's fine but what his body looks like has nothing to do with who he is as a person right? So, there was this really interesting response to the body shaming of this guy that people didn't like right, they were trying to make fun of his body but then people were like, "Don't do that, that's not cool." You know?...So that 1-like, it was like very interesting. So there does seem to be this conscious, consciousness of body shaming as being uncool...Y You know? Still happens but it's not cool anymore. 
Thus, while acknowledging that it was normative for female Hollywood actors to lose weight and for naked fat flesh to motivate derision, progress was evident in the form of resistance to these expectations.

While most participants did feel that cultural norms were shifting to more size inclusivity, participants also qualified these shifts in nuanced ways. For example, several participants felt that the range of acceptable body types was expanding but that representation was still limited to relatively smaller bodies.

I think that maybe we're starting to see some changes with... full-sized models. But even they are not, you know, not, necessarily, struggling with the level of ... obesity that a good many people are within society, I would say. (Charlotte)

Several participants were less sure whether society was becoming more body-accepting. These participants felt society was now 'more visual' and objectifying, or that body standards were now more exacting. Comments were made regarding inescapable social media, objectification of women during the Trump Presidential campaign, advertisements, and reality TV. The persistent ubiquity of idealised bodies in media was repeatedly emphasised.

You see all these beautiful people on TV, and you look around and you don't see anybody, so you're likely to dismiss that as, "Oh, it's just TV." But then, you also still say, "I wish I looked like that on TV." (Madison)

Madison's comment highlights a juxtaposition between the conscious mind of knowing bodies on television are not accurate reflections of society's bodies, yet still yearning to conform to such unattainable expectations. 
Ava and Riley also felt that positive portrayals of fat bodies were emerging, but that these were still counter to the hegemonic portrayal of thinner bodies or for fat bodies to be concealed:

I mean, the media is in your face all the time. Magazine, you can pick it up, you don't pick it up, but it's in your face all the time. I'm sure that there's ... That adds to it...I mean you don't see chubby women modeling. Now a little bit it's starting, but it's more like rebellion. Oh yeah, it's cool. I think that's good. ... I mean, I was like surprised there's this really heavy yoga teacher in the media. She's beautiful. She's got great skin. And she can do every position with a smile and I thought ... And... she doesn't hide her body. I'd always hide my body with loose clothing... I thought, "You know what? She's right." Such leaders in our society can be contagious. (Ava)

You look at like the different, I don't wanna say movie stars, but the different famous people...And I think that some of them are probably doing a very good job of body acceptance because they're out there and they don't care, they're gonna wear that leather skirt. They're gonna wear those leggings no matter... what. But then I'm like, "Where ... Who, who does their shopping? Because those leggings look really good on them ... even if they're (laughter) and even if they're what they call a plus size?" That looks really good on them. They got a really good- where do they get them? (laughs) Like, where do they get that one, you know... but then I also think, too that there still is a v-, a very big movement for people to be thin. (Riley)

Madeline problematised the 'comic' portrayal of higher-weight persons on television: 
On the one hand it's getting better because you see more large-sized women ... American Housewife is a sitcom where there's this mouthy comedian who's the wife. .... But she's heavier... they... continue to address her as being the heavy mom... the neighbor's the skinny mom ... who buys her a FitBit and is kinda shoving her, you-should-lose-weight values down her throat. So you know, like, the first time I saw it I thought, "It's nice to see, like a, what, someone that I can relate to and her mom, kind of issues." I'm like, I can relate to this woman, you know. But then the skinny neighbor comes over and buys her a FitBit and the mo, fat mom throws it away ... they're addressing it in a...comedic way. But again, it's kinda like they're fat shaming her that she shouldn't be ... And she's not fat. She's just like, normal, I think.

Thus, in describing representativeness during interviews, participants were highlighting exceptions, calling attention to the incremental, positive changes they identified to a generally fat-phobic society. Participants felt individuals nevertheless continued to encounter substantial pressures to meet media-influenced appearance standards.

\section{Lip Service}

While often expressing a belief that progress was occurring, participants could be sceptical and hesitant to take the body-positivity movements in clothing and media as genuine or producing more than incremental change. Participants questioned the motivations of seemingly empowering messages and portrayals, what Chloe termed, 'lip service', and whether changes in discourse produced actual changes in their everyday lives. For example, Olivia expressed frustration with the clothing industry that purported to be 'body positive': 
I'll see it on, on TV or something... "Gosh, you, you guys portray us out to be this body positive and all that, but you don't sell things to make it that way." You know what I mean? Because then you're like, you sit there, it's like, "God, do I have to be skinnier for this? Like, do I have to lose weight just to get that dress?"

Thus, body positivity was sometimes recognised as merely a corporate buzzword for industries whose products would remain out-of-reach.

Others questioned the motives of those engaging in anti-fat shaming discourse:

You have this "You should never fat shame" but then on the exact same, you know that woman who you remember the mom who had like three kids and like went down to like 0 and she fat shamed someone, and then there was this article recently how she felt bad about that. Because she still realises how hard it is to lose weight. And she's still perfect. Like, you do not really feel bad. You know what I mean? Like, you're just trying to get back in the news. (Emily)

In general, however, participants felt that the increasing institutionalised, corporatised, and social media pushes for greater diversity were nevertheless motivating (moderately) more size-inclusive representation.

\section{Inclusive Cultures}

Cultural body acceptance was sometimes referenced as one component of greater appreciation of overall diversity and inclusivity in society. An appreciation for a diverse society was tied to acceptance and representation of gender, sexual, racial, and ethnic variety, but also body type. 
You look at the TV shows and stuff that are out now. Not everybody is that perfect, whatever that perfect... size is... and it's not just body size. It's everything. I mean, the diversity is. And even my [partner] said that. He goes, "Have you noticed the commercials in the last few months? Very diverse." I mean, and I think it's wonderful...I mean, you got people of all walks of life and you know they're showing...even ... some of the jewelry commercials I noticed. You know... it's not just, oh, this man and this woman. ... it's ... these two men proposing ...it's great. (Aria)

You see strong figures, in different...avenues like politics, and fashion, and TV that are all different genders, all different races, and all different sizes. ... you could see stars as big as life and they're not 100 pounds... you see them on covers of magazines and ... like Oprah Winfrey, Ellen DeGeneres... just ton of people that you can think of, you know that are supportive role models for girls where we really didn't have that as much... growing up back in the '80s. (Peyton)

I think it's coming out at the same time when Americans are concerned about the hatred against different ethnicities as well... so ... they're saying love each other whether you're Muslim or Indian or Jewish or Korean or skinny or fat. (Ava)

Occasionally, both greater body acceptance and overall appreciation for diversity and inclusion was attached to generational cohorts.

It's not just the media, not just a male-dominated society, it's ... it's more so of a message of equality-... you know, that all genders, and that... all races and everyone should be treated equally, that's more predominant now than I saw when I was a child... so I think that does help because I do see...children now in my 
daughter's school, who are all from different walks of life, all different races and religions, and they get along so well ... and there are no thoughts in her school of "This person's different", these children are starting to see each other as equals (Peyton).

I don't know I think there's a lot of the people call it political correctness but I just call it being nice...but this idea that we should be nice to people and not make fun of them for who they are, what they look like or anything, there is that sort of thing. The generation that I see now like in my students they seem to be more aware and more accepting of people that are different, they're a lot more than my generation was. You know? That the future might not be so bad because we really seem to be working at it and it's just not as cool as it used to be you know? (Harper)

However, similar to participants' criticism of body acceptance 'lip service', experiences in everyday life and political consciousness alerted participants to limitations of cultural emphases on diversity and inclusion. The overall progression of social tolerance did not translate into local contexts for Ava. She referred to another area as 'more accepting' of sexual minorities than the area she was living in, and she stated that discrimination locally had risen as local Neo-Nazi groups were 'feeling more empowered'. Similarly, Layla described the limitations to the shifts she saw in body acceptance and linked this to other forms of exclusion:

We are not even like on- the 101 level of fat acceptance yet, we're like, intro to fat acceptance, I feel like. (laughter) So it's ... interesting. I feel like it's there, but, you 
know, I also feel like too, as long as people have an avenue to "other", or shame other people, they're gonna take advantage of that, too.

Layla indicated examples of body acceptance remained exceptional. She also identified increasing marginalisation of other social groups throughout data collection. She felt other marginalised groups would be the focus of escalating intolerance and backlash against progressive values in society. Following data collection, she sent the interviewer an article from a hate publication regarding anti-racist activist, Heather Heyer, who was murdered while protesting white nationalists at a White supremacist rally in Charlottesville, Virginia. The article was rife with misogyny and anti-fatness, which would seem to confirm Layla's predictions.

\section{Discussion}

Midwestern American women of higher weight perceive that there is greater (albeit still problematic) representation of higher-weight bodies and more effort to incorporate size diversity in a generally more inclusive society. Critically, while participants often focused on representation that is more inclusive and noted positive changes to society, they were often contextualising these as exceptions within a largely fat-phobic social context. Participants also felt that the increased representation nevertheless remained focused on their weight and its problematic nature. Although several mainstream television shows now feature a fat character whose weight is not used as a punchline, more common are fat characters who represent discontent or who pre-emptively poke fun at their own bodies (Zimdars, 2015).

Further, weight stigma and messages encouraging disordered eating remain pervasive in media such as reality television and digital formats (Lupton, 2018; Monaghan, 2008; Raisborough, 2016), although other voices and a more 'benevolent', albeit paternalist and classist, tone may 
have entered some discursive space (Lupton, 2018; Raisborough, 2016). For example, higherweight individuals in reality television shows are objects of surveillance and depicted as in need of weight loss in order to successfully 'fit in' to society (Backstrom, 2012), what Raisborough (2016) calls 'redemption porn'. Few people in reality television are presented as valourising self-acceptance (Zimdars, 2015). Thus, as noted by the participants in the present study, greater representation and less weight-centric characterisation of larger characters is still needed. In contrast, certain higher-weight stars, such as Melissa McCarthy, present an alternative onscreen embodiment of circumscribed deviance (Meeuf, 2016). As Meeuf (2016) indicates in his analysis of the incongruence of McCarthy's polite celebrity persona with the lower-class-coded characters she portrays, media-endorsed self-acceptance is open only to those able to meet White, middle-class standards and to purchase a commodified version of self-confidence. Notably, White, cis, and straight voices continue to dominate the body acceptance movement (Cooper, 2016; Pausé, 2015).

Participants also noted that even the more inclusive bodily representations they encounter do not endorse a full range of body diversity, pointing out that many spokespersons of body acceptance or positivity (at least those with whom they were familiar) were still relatively slender. Overrepresentation of thin, conventionally, attractive white women within 'body positive' spaces is a concern among the fat acceptance community (Cwynar-Horta, 2016). Indeed, popular body positivity messaging tends to focus more on neo-liberal, postfeminist concerns of appearance, choice, and empowerment - and not the political or social transformation of expectations on women to submit their bodies to ongoing surveillance and to achieve 'femininity', 'beauty', and 'sexiness' (Caldeira \& De Ridder, 2017; Cwynar-Horta, 2016; Gill, 2016; Sastre, 2014; Zaslow, 2018). These trends are particularly noticeable in digital media spaces. As Pausé (2015) notes, 
although anti-assimilationist fat activism is available now to anyone with access to a computer, it remains a challenge to counter neoliberal edicts to do both fatness and fat activism 'apologetically' - that is, by embodying health and 'healthy choices'. An analysis of Fatosphere postings emphasises the difficulties in sustaining a non-dieting, fat acceptance approach in a fatphobic social clime, considering the advantages of thin privilege (Donaghue \& Clemitshaw, 2012). Further, while designed as venues for body acceptance and inclusion (Dickins, Browning, Feldman, \& Thomas, 2016), even this fat-positive social media platform can be infiltrated by weight stigmatising posts (Webb, Vinoski, Bonar, Davies, \& Etzel, 2017). Thus, supposedly safe spaces are susceptible to mixed messaging, and social media in general provides a powerful platform for fat shaming (Jeon, Hale, Knackmuhs, \& Mackert, 2018; Lydecker et al., 2016). Several participants also commented on the much-hailed body-positive shift within the fashionbeauty complex, but felt that many organisations were simply paying lip service to body acceptance. The Dove beauty campaign was given as one example of increasing diversity within the media. However, participants also noted that the bodies present in such campaigns did not capture the full range of bodies in reality. Brown (2005) contends that the media's focus is on acceptance of 'average' sized women (around sizes 14 and 16), and that rather than reflecting true acceptance of body diversity, this supposed cultural shift represents the 'idealization of some [the thin], the acceptance of the average, and the denigration of others [the fat]' (Brown, 2005, p. 248). Indeed, the fashion-beauty complex's construction of fatness as unappealing, what Kwan and Graves (2013) have deemed the 'aesthetic frame' of fatness, remains a dominant framing of body size. Several participants commented on how even as they noticed more 'plus-sized' models and a growing industry of plus-sized clothing, while, ironically, often not being able to find clothing in their size, these representations were notable for being exceptions to the rule. 
Even within the fashion industry, plus-size models are portrayed as separate, and not equal (Peters, 2014).

Additionally, there is an illogic to a campaign that supposedly resists beauty standards while also pushing the idea that Dove's products will help women look beautiful, an apparently essential part of being a woman (Johnston \& Taylor, 2008). Indeed, exposure to the Dove beauty campaign is found to elicit both strong positive and negative emotions and does not significantly influence thin ideal internalisation (Kraus \& Myrick, 2018). Thus, while corporations have coopted the language of body positivity and self-acceptance, seemingly attempting to subvert beauty standards through their product, they are simultaneously attempting to promote consumerism to achieve standards of beauty. Even the diet industry has appropriated the language and symbols of the fat acceptance movement to sell us weight-loss under a different guise (Cooper, 2016).

Interestingly, participants more commonly referred to 'body positivity' than they did to 'fat acceptance' (and indeed, no participants spoke of 'fat activism'). This suggests that body positivity may have achieved greater penetration among Midwestern women. Yet, 'body positivity' is genealogically and epistemologically distinct from body acceptance, and even further removed from fat activism (Cooper, 2016; Ellison, 2017). The repeated message to be 'positive' about one's body places an externally imposed edict on (mostly) women and girls, with those who struggle to do so being given yet another way to fail in their performance of womanhood. Further, corporate campaigns, such as the Dove Real Beauty campaign, that focus on 'body positivity' situate the 'problem' with women's bodies entirely within themselves and something that can be stopped simply by changing their viewpoint - essentially blaming the 
victim - and absolves the fashion-beauty complex, and the systemic objectification of women's bodies in general, from any culpability (Gill \& Elias, 2014). As Wann (2017) warns:

The new and popular term "body positive" expands fat lib to address more experiences of alienation about embodiment but also risks avoiding the hard work of challenging fat oppression. To all of this, I would advise: accept no substitutes for fat liberation as part of an intersectional challenge to all oppressions (pg. 76).

Perhaps one of the most interesting themes to emerge was the recurring association participants made between the ascendancy of body acceptance messages and media representativeness of higher-weight bodies with the evolution of a more inclusive society in general. Indeed, generally speaking, there is greater racial and ethnic diversity in primetime television in the past two decades, although Latinos, Asians, and Indigenous characters remain vastly under-represented, and Black representation fluctuates (Tukachinsky, Mastro, \& Yarchi, 2015). Explicit representation of LGBT (lesbian, gay, bisexual, and trans) individuals in, for example, television advertising, has also increased substantially (Nölke, 2018). However, similar to concerns raised over body positivity content, such representations often focus on limited intersections - White, middle-class, middle-aged or young gay men. Non-femme lesbians, trans women, and bisexuals are rarely portrayed. Intersex and asexual characters are completely invisible, and portrayals continue to reproduce largely heteronormative and domestic portrayals of 'gayness' that are more likely to appeal to non-gay audiences (Nölke, 2018). Thus, representation of diversity is increasing but remains within a narrow realm of acceptability to dominant groups. As part of the, at least superficial, trend toward a more open and accepting culture, several participants also raised the phenomenon of increased vocalisation against fat-shaming behaviour. Certainly, a number of recent high-profile social media outcries against blatant fat-shaming have 
resulted in widespread recrimination and financial or legal penalties for perpetrators. Examples of such censure and consequences include the move to ban advertisements featuring unrealistic bodies from London transport (Jackson, 2016); the removal of fat-phobic fitness centre advertisements (Schlossberg, 2016); and the loss of a job for fat-shaming YouTube comedian Nicole Arbour (Bogart, 2015). However, although this may indicate some progress has been made, research suggests that such viral outrage may have paradoxical effects, creating sympathy for the transgressor (Sawaoka \& Monin, 2018). Indeed, content analysis of articles about fatness and/or obesity on five major news aggregators, and the comments that followed them, indicated an extreme and sometimes vitriolic resistance against body acceptance messages, from both authors and public commentators (Cain, Donaghue, \& Ditchburn, 2017). Further, many writers decrying the shaming of higher-weight individuals nevertheless position weight as problematic and individuals with higher weights as 'sufferers' in need of compassion and assistance (Cain et al., 2017).

It could be argued that fat activism has benefited from 'social movement spillover' (Saguy \& Ward, 2011) from the advancement of other social movements, such as movements for gay, disability, and racial liberation. Fostered by overlapping memberships and networks between marginalised groups, ideologies and language have migrated into the fat acceptance movement, such as the concept of 'coming out' as fat and being unapologetic about one's body (Saguy \& Ward, 2011). Importantly, though, compared with legislative protections achieved by other groups, legal victories for fat activism remain limited (Harker \& von Liebenstein, 2018; Solovay, 2000). While there are laws against discriminating on the basis of race, religion, sex, nationality, age, and disabilities, body type and being fat are still not protected (with the exclusion of some cities and the state of Michigan) in the United States (NAAFA, 2016). Thus, independent of an 
individual's ability or work ethic, discrimination based solely on body type remains legally acceptable. Therefore, despite progress made by many socially marginalised groups, the 'spillover effect' for fat advocacy remains to date insufficient to achieve true legal, political, and social equality.

Taken together, these findings have implications for the body acceptance movement in the United States. While ideal body types may be changing, and the 'thin ideal' has expanded into new forms of ideal body types, including the 'athletic ideal' and the 'curvy ideal', such depictions may have less empowering effects than messaging promoting acceptance of all body sizes, or indeed, a focus away from women's appearance entirely (Betz \& Ramsey, 2017). The apparent successes of decades of activism of the movement are often superficial and cynical corporatisations of the original goals. Fat activism may need to move conversations away from health or appearance and embracing a queerer, ambiguous rejection of neoliberal body projects (Afful \& Ricciardelli, 2015; Brady, Gingras, \& Aphramor, 2013; Chalklin, 2016). A truly powerful body acceptance movement will require room for unconditional bodily diversity, a genuine commitment to rectifying intersectional disadvantage, and a focus on advocacy to effect meaningful societal change (Cooper, 2016; Maor, 2012; Nash \& Warin, 2017; von Liebenstein, 2012).

\section{Strengths and Limitations}

This study used repeated interviews to explore Midwestern women of higher weight's perceptions of cultural body acceptance over time and, to our knowledge, is the one of the first studies to use a longitudinal design to capture targets' perceptions of changing societal attitudes to fat bodies. Retention was high, and the repeated interviews, iterative analysis, and detailed audit trail allowed for the gathering of rich data that were firmly contextualised in participants' 
lives, the ability to clarify findings and incorporate emergent themes over repeated interviews, and the development of strong rapport (Creswell, 2012; J. Smith \& Osborn, 2008). The volume of data gathered was also considerable, including 53 interviews and their associated field-notes. One possible limitation is that participants may have been sensitised to identifying cultural change due to their participation in the longitudinal study; however, participant responses regarding perceptions of cultural change remained quite consistent across time points. Additionally, although the sample was small, homogenous, and cannot allow for generalisability, these are preferred characteristics for such in-depth analysis (J. Smith \& Osborn, 2008). Participants will not be representative of the broader region in which the study was conducted given the small sample size and the setting of a small University city. The findings should be tested for transferability in other settings and among more racially or ethnically diverse populations, male-identified participants, and individuals across different sexual orientations. Interestingly, this study took place in the state of Michigan, the only state in the USA that includes weight as a protected category in its anti-discrimination legislation, and has done so since 1976. However, it is beyond the scope of the present study to determine whether the existence of this legislation has influenced individual and social perceptions of fat acceptance in the state. Indeed, little is currently known about the impact of anti-weight-discrimination legislation and policies on changing attitudes about high-weight individuals (Goldberg, Meadows, \& Daníelsdóttir, 2019), and future research on this topic may be of interest from both a sociological and policy perspective.

\section{Conclusions}

In conclusion, Midwestern women of higher weight noted positive advances in body diversity in media, greater availability of clothing, and more resistance to body shaming narratives. 
However, limitations were still apparent in the upper ceiling of acceptable bodies, exclusion of certain body types, and likelihood of corporatised messages to induce change. Additionally, while participants recognised changes in cultural discourse, these did not necessarily translate into more inclusive experiences in their everyday lives. Indeed, participants noted that discursive commitments to inclusion often seemed empty or disingenuous. Ultimately, more universal and subversive messages may be necessary to advance body acceptance - not simply raising the upper limit of acceptable body types. 


\section{References}

Afful, A. A., \& Ricciardelli, R. (2015). Shaping the online fat acceptance movement: Talking about body image and beauty standards. Journal of Gender Studies, 24(4), 453-472. https://doi.org/10.1080/09589236.2015.1028523

Backstrom, L. (2012). From the freak show to the living room: Cultural representations of dwarfism and obesity. Sociological Forum, 27(3), 682-707. https://doi.org/10.1111/j.1573-7861.2012.01341.x

Betz, D. E., \& Ramsey, L. R. (2017). Should women be ‘All About That Bass?’: Diverse bodyideal messages and women's body image. Body Image, 22, 18-31. https://doi.org/10.1016/j.bodyim.2017.04.004

Blake, C. E., Hebert, J. R., Lee, D. C., Adams, S. A., Steck, S. E., Sui, X., ... Blair, S. N. (2013). Adults with greater weight satisfaction report more positive health behaviors and have better health status regardless of BMI. Journal of Obesity, Article ID 291371. https://doi.org/10.1155/2013/291371

Bogart, N. (2015, November 9). YouTube comedian Nicole Arbour reportedly loses job over fatshaming video. GlobalNews. Ca. Retrieved from https://globalnews.ca/news/2215339/youtube-comedian-nicole-arbour-reportedly-losesjob-over-fat-shaming-video/

Bombak, A. E. (2014). Obesity, Health-at-Every-Size, and public health policy. American Journal of Public Health 104(2): e60-e67. https://doi.org/10.2105/AJPH.2013.301486

Brady, J., Gingras, J., \& Aphramor, L. (2013). Theorizing health at every size as a relationalcultural endeavour. Critical Public Health, 23(3), 345-355. https://doi.org/10.1080/09581596.2013.797565 
Brown, S. (2005). An obscure middle ground: Size acceptance narratives and photographs of 'real women'. Feminist Media Studies, 5(2), 246-249. https://doi.org/10.1080/14680770500112368

Cain, P., Donaghue, N., \& Ditchburn, G. (2017). Concerns, culprits, counsel, and conflict: A thematic analysis of "obesity" and fat discourse in digital news media. Fat Studies, 6(2), 170-188. https://doi.org/10.1080/21604851.2017.1244418

Caldeira, S. P., \& De Ridder, S. (2017). Representing diverse femininities on Instagram: A case study of the body-positive @effyourbeautystandards Instagram account. Catalan Journal of Communication \& Cultural Studies, 9(2), 321-337. https://doi.org/info:doi/10.1386/cjcs.9.2.321_1

Chalklin, V. (2016). Obstinate fatties: Fat activism, queer negativity, and the celebration of 'obesity'. Subjectivity, 9(2), 107-125. https://doi.org/10.1057/sub.2016.3

Cooper, C. (2016). Fat activism: A radical social movement. Bristol, UK: HammerOn Press. Creswell, J. W. (2012). Qualitative Inquiry and Research Design: Choosing Among Five Approaches. SAGE Publications.

Cwynar-Horta, J. (2016). The commodification of the body positive movement on Instagram. Stream: Inspiring Critical Thought, 8(2), 36-56.

Dickins, M., Browning, C., Feldman, S., \& Thomas, S. (2016). Social inclusion and the Fatoshpere: The role of an online weblogging community in fostering social inclusion. Sociology of Health \& Illness. https://doi.org/10.1111/1467-9566.12397

Donaghue, N., \& Clemitshaw, A. (2012). 'I'm totally smart and a feminist...and yet I want to be a waif': Exploring ambivalence towards the thin ideal within the fat acceptance 
movement. Women's Studies International Forum, 35(6), 415-425. https://doi.org/10.1016/j.wsif.2012.07.005

Ellison, J. (2017). Fat activism: A radical social movement, by Charlotte Cooper. Women's Studies, 46(3), 257-259. https://doi.org/10.1080/00497878.2017.1288048

Elo, S., \& Kyngäs, H. (2008). The qualitative content analysis process. Journal of Advanced Nursing, 62(1), 107-115. https://doi.org/10.1111/j.1365-2648.2007.04569.x

Emerson, R. M., Fretz, R. I., \& Shaw, L. L. (2011). Writing ethnographic fieldnotes (2nd ed.). Chicago, IL: University of Chicago Press.

Gard, M., \& Wright, J. (2005). The obesity epidemic: Science, morality and ideology. Abingdon, UK: Routledge.

Germov, J., \& Williams, L. (1996). The epidemic of dieting women: the need for a sociological approach to food and nutrition. Appetite, 27(2), 97-108. https://doi.org/10.1006/appe.1996.0038

Gill, R. (2016). Post-postfeminism?: New feminist visibilities in postfeminist times. Feminist Media Studies, 16(4), 610-630. https://doi.org/10.1080/14680777.2016.1193293

Gill, R., \& Elias, A. S. (2014). ‘Awaken your incredible’: Love your body discourses and postfeminist contradictions. International Journal of Media and Cultural Politics, 10(2), 179-188. https://doi.org/10.1386/macp.10.2.179_1

Goldberg, D. S., Meadows, A., \& Daníelsdóttir, S. (2019). Fat stigma: Legal and political challenge of adding weight as a protected characteristic under equality and antidiscrimination law. Manuscript in preparation. 
Harker, Y., \& von Liebenstein, S. (2018). Protected classes in international anti-discrimination legislation and their potential to protect against weight discrimination. Manuscript in preparation.

Hatzenbuehler, M. L., Keyes, K. M., \& Hasin, D. S. (2009). Associations between perceived weight discrimination and the prevalence of psychiatric disorders in the general population. Obesity, 17(11), 2033-2039. https://doi.org/10.1038/oby.2009.131

Himmelstein, M. S., Puhl, R. M., Quinn, D. M., \& Gorber, B. (2017). Intersectionality: An understudied framework for addressing weight stigma. American Journal of Preventive Medicine, 53(4), 421-431. https://doi.org/10.1016/j.amepre.2017.04.003

Jackson, J. (2016, June 13). Sadiq Khan moves to ban body-shaming ads from London transport. Retrieved 1 November 2018, from https://www.theguardian.com/media/2016/jun/13/sadiq-khan-moves-to-ban-bodyshaming-ads-from-london-transport

Jeon, Y. A., Hale, B., Knackmuhs, E., \& Mackert, M. (2018). Weight stigma goes viral on the Internet: Systematic assessment of YouTube comments attacking overweight men and women. Interactive Journal of Medical Research, 7(1), e6. https://doi.org/10.2196/ijmr.9182

Johnston, J., \& Taylor, J. (2008). Feminist consumerism and fat activists: A comparative study of grassroots activism and the Dove Real Beauty Campaign. Signs, 33(4), 941-966. https://doi.org/10.1086/528849

Kraus, A., \& Myrick, J. G. (2018). Feeling bad about feel-good ads: The emotional and bodyimage ramifications of body-positive media. Communication Research Reports, 35(2), 101-111. https://doi.org/10.1080/08824096.2017.1383233 
Kwan, S., \& Graves, J. (2013). Framing fat: Competing constructions in contemporary culture. Rutgers University Press.

Lupton, D. (2018). Fat (2nd ed.). London, UK: Routledge.

Lydecker, J. A., Cotter, E. W., Palmberg, A. A., Simpson, C., Kwitowski, M., White, K., \& Mazzeo, S. E. (2016). Does this Tweet make me look fat? A content analysis of weight stigma on Twitter. Eating and Weight Disorders, 21(2). https://doi.org/10.1007/s40519016-0272-X

Maor, M. (2012). The body that does not diminish itself: Fat acceptance in Israel's lesbian queer communities. Journal of Lesbian Studies, 16(2), 177-198.

https://doi.org/10.1080/10894160.2011.597660

Meeuf, R. (2016). Class, corpulence, and neoliberal citizenship: Melissa McCarthy on Saturday Night Live. Celebrity Studies, 7(2), 137-153.

https://doi.org/10.1080/19392397.2015.1044758

Monaghan, L. (2008). Men and the war on obesity. Abingdon, UK: Routledge.

NAAFA. (2016). Laws in place. Retrieved 2 November 2018, from https://www.naafaonline.com/dev2/education/laws.html

Nash, M., \& Warin, M. (2017). Squeezed between identity politics and intersectionality: A critique of 'thin privilege' in Fat Studies. Feminist Theory, 18(1), 69-87. https://doi.org/10.1177/1464700116666253

Nölke, A.-I. (2018). Making diversity conform? An intersectional, longitudinal analysis of LGBT-specific mainstream media advertisements. Journal of Homosexuality, 65(2), 224255. https://doi.org/10.1080/00918369.2017.1314163 
O'Hara, L., \& Taylor, J. (2018). What's wrong with the 'war on obesity'? A narrative review of the weight-centered health paradigm and development of the $3 \mathrm{C}$ Framework to build critical competency for a paradigm shift. SAGE Open, $8(2)$.

https://doi.org/10.1177/2158244018772888

Pausé, C. (2015). Rebel heart: Performing fatness wrong online. M/C Journal, 18(3). Retrieved from http://www.journal.media-culture.org.au/index.php/mcjournal/article/view/977

Peters, L. D. (2014). You are what you wear: How plus-size fashion figures in fat identity formation. Fashion Theory, 18(1), 45-71. https://doi.org/10.2752/175174114X13788163471668

Raisborough, J. (2016). Fat bodies, health and the media. London, UK: Palgrave Macmillan.

Rodin, J., Silberstein, L., \& Streigel-Moore, R. (1984). Women and weight: A normative discontent. Nebraska Symposium on Motivation, 32, 267-307.

Saguy, A. C., \& Ward, A. (2011). Coming out as fat: Rethinking stigma. Social Psychology Quarterly, 74(1), 53-75. https://doi.org/10.1177/0190272511398190

Saldaña, J. (2003). Longitudinal qualitative research: Analyzing change through time. Walnut Creek, CA: Rowman Altamira.

Saldaña, J. (2016). The coding manual for qualitative researchers (3rd ed.). Los Angeles, CA: Sage.

Sastre, A. (2014). Towards a radical body positive. Feminist Media Studies, 14(6), 929-943. https://doi.org/10.1080/14680777.2014.883420

Sawaoka, T., \& Monin, B. (2018). The paradox of viral outrage. Psychological Science, 0956797618780658. https://doi.org/10.1177/0956797618780658 
Schlossberg, M. (2016). A major gym chain is under fire after an actress called out its fatshaming ads. Retrieved 16 December 2017, from http://uk.businessinsider.com/goldsgym-fat-shaming-ad-causes-controversy-2016-8?r=US\&IR=T

Smith, J., \& Osborn, M. (2008). Interpretative phenomenological analysis. In J. Smith (Ed.), Qualitative psychology: A practical guide to research methods (pp. 53-80). London, UK: Sage.

Smith, N. (2003). Cross-sectional profiling and longitudinal analysis: Research notes on analysis in the longitudinal qualitative study, 'Negotiating Transitions to Citizenship'. International Journal of Social Research Methodology, 6(3), 273-277. https://doi.org/10.1080/1364557032000091888

Solovay, S. (2000). Tipping the scales of justice: Fighting weight-based discrimination. Amherst, NY: Prometheus Books.

Tantleff-Dunn, S., Barnes, R. D., \& Larose, J. G. (2011). It's not just a “woman thing:” The current state of normative discontent. Eating Disorders, 19(5), 392-402. https://doi.org/10.1080/10640266.2011.609088

Thomson, R., \& Holland, J. (2003). Hindsight, foresight and insight: The challenges of longitudinal qualitative research. International Journal of Social Research Methodology, 6(3), 233-244. https://doi.org/10.1080/1364557032000091833

Tukachinsky, R., Mastro, D., \& Yarchi, M. (2015). Documenting portrayals of race/ethnicity on primetime television over a 20 -year span and their association with national-level racial/ethnic attitudes. Journal of Social Issues, 71(1), 17-38. https://doi.org/10.1111/josi.12094 
von Liebenstein, S. (2012). Confronting weight discrimination in Germany: The foundation of a fat acceptance organization. Fat Studies, 1(2), 166-179. https://doi.org/10.1080/21604851.2012.643681

Wann, M. (2017). Fat oppression as a source of inspiration: A case history of the FAT!SO? Book. Fat Studies, 6(1), 67-76. https://doi.org/10.1080/21604851.2017.1228419

Webb, J. B., Vinoski, E. R., Bonar, A. S., Davies, A. E., \& Etzel, L. (2017). Fat is fashionable and fit: A comparative content analysis of Fatspiration and Health at Every Size ${ }^{\circledR}$ Instagram images. Body Image, 22, 53-64. https://doi.org/10.1016/j.bodyim.2017.05.003

Wright, J. (2004). Post-structural methodologies: The body, schooling and health. In J. Evans, B. Davies, \& J. Wright (Eds.), Body knowledge and control. Studies in the sociology of physical education and health (pp. 19-31). London: Routledge.

Zaslow, E. (2018). \#Iammorethanadistraction: Connecting local body politics to a digital feminist movement. In J. Keller \& M. Ryan (Eds.), Emergent feminisms: Complicating a postfeminist media culture. New York, NY: Routledge. https://doi.org/10.4324/9781351175463-6

Zimdars, M. (2015). Fat acceptance TV?: Rethinking reality television with TLC's Big Sexy and the Carnivalesque. Popular Communication, 13(3), 232-246.

https://doi.org/10.1080/15405702.2015.1048344 